\title{
Investigating the evolving microstructure of lithium metal electrodes in 3D using $X$-ray Computed Tomography
}

DOI:

10.1039/C7CP02872E

Document Version

Accepted author manuscript

Link to publication record in Manchester Research Explorer

\section{Citation for published version (APA):}

Taiwo, O. O., Finegan, D. P., Paz-García, J. M., Eastwood, D., A.J. Bodey, Rau, C., Hall, S. A., Brett, D. J. L., Lee, P., \& Shearing, P. R. (2017). Investigating the evolving microstructure of lithium metal electrodes in 3D using X-ray Computed Tomography. Physical Chemistry Chemical Physics. https://doi.org/10.1039/C7CP02872E

\section{Published in:}

Physical Chemistry Chemical Physics

\section{Citing this paper}

Please note that where the full-text provided on Manchester Research Explorer is the Author Accepted Manuscript or Proof version this may differ from the final Published version. If citing, it is advised that you check and use the publisher's definitive version.

\section{General rights}

Copyright and moral rights for the publications made accessible in the Research Explorer are retained by the authors and/or other copyright owners and it is a condition of accessing publications that users recognise and abide by the legal requirements associated with these rights.

\section{Takedown policy}

If you believe that this document breaches copyright please refer to the University of Manchester's Takedown Procedures [http://man.ac.uk/04Y6Bo] or contact uml.scholarlycommunications@manchester.ac.uk providing relevant details, so we can investigate your claim.

\section{OPEN ACCESS}



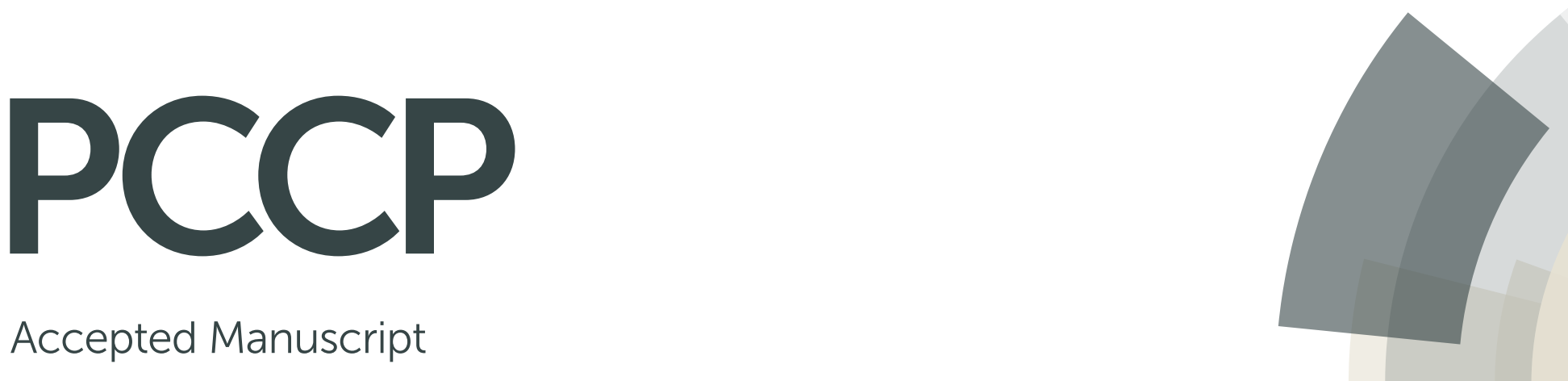

\section{Accepted Manuscript}

This article can be cited before page numbers have been issued, to do this please use: O. O. Taiwo, D. P. Finegan, J. M. Paz Garcia, D. S. Eastwood, A. Bodey, C. Rau, S. Hall, D. Brett, P. D. Lee and P. Shearing, Phys. Chem. Chem. Phys., 2017, DOI: 10.1039/C7CP02872E.

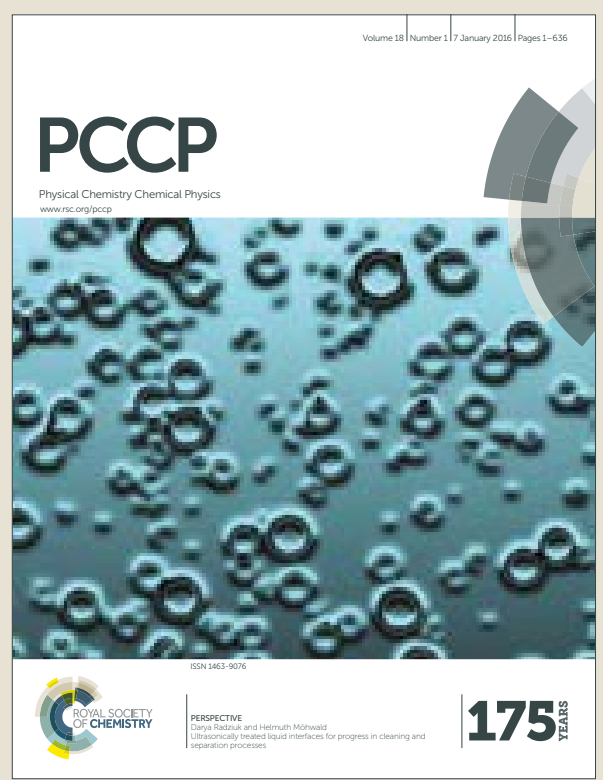

This is an Accepted Manuscript, which has been through the Royal Society of Chemistry peer review process and has been accepted for publication.

Accepted Manuscripts are published online shortly after acceptance, before technical editing, formatting and proof reading. Using this free service, authors can make their results available to the community, in citable form, before we publish the edited article. We will replace this Accepted Manuscript with the edited and formatted Advance Article as soon as it is available.

You can find more information about Accepted Manuscripts in the author guidelines.

Please note that technical editing may introduce minor changes to the text and/or graphics, which may alter content. The journal's standard Terms \& Conditions and the ethical guidelines, outlined in our author and reviewer resource centre, still apply. In no event shall the Royal Society of Chemistry be held responsible for any errors or omissions in this Accepted Manuscript or any consequences arising from the use of any information it contains. 


\section{PCCP}

\section{Paper}

\section{Investigating the evolving microstructure of lithium metal electrodes in 3D using X-ray Computed Tomography}

Received 00th January 20xx, Accepted 00th January 20xx

DOI: $10.1039 / x 0 x \times 00000 x$

www.rsc.org/

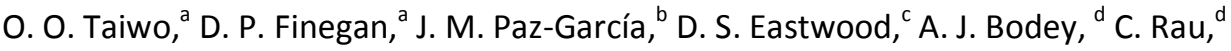 \\ S. A. Hall, ${ }^{b}$ D. J. L. Brett, ${ }^{a}$ P. D. Lee ${ }^{c}$ and P. R. Shearing*a
}

The growth of electrodeposited lithium microstructures on metallic lithium electrodes has prevented their use in rechargeable lithium batteries due to early performance degradation and safety implications. Understanding the evolution of lithium microstructures during battery operation is crucial for the development of an effective and safe rechargeable lithium-metal battery. This study employs both synchrotron and laboratory X-ray computed tomography to investigate the morphological evolution of the surface of metallic lithium electrodes during a single cell discharge and over numerous cycles, respectively. The formation of surface pits and the growth of mossy lithium deposits through the separator layer are characterised in threedimensions. This has provided insight into the microstructural evolution of lithium--metal electrodes during rechargeable battery operation, and further understanding of the importance of separator architecture in mitigating lithium dendrite growth.

\section{Introduction}

Compared to graphite-based negative electrodes currently used in commercial rechargeable lithium (Li) batteries, metallic lithium offers several advantages: $L i$ has an extremely high specific capacity of $3800 \mathrm{mAhg}^{-1}$ which is tenfold higher than that of lithiated graphite $\left(372 \mathrm{mAhg}^{-1}\right)$, and it also has the lowest negative electrochemical potential ($3.04 \mathrm{~V}$ vs. the standard hydrogen electrode ${ }^{1}$ ). However, Li metal suffers severe safety and efficiency challenges that have prevented its use as a negative electrode in commercial rechargeable Li batteries. Many of these challenges are associated with morphological changes that occur on the lithium metal surface upon repeated charge-discharge

\footnotetext{
a. Electrochemical Innovation Lab, Department of Chemical Engineering, University College London, Torrington Place, London WC1E 7JE, UK.

b. Division of Solid Mechanics, Lund University, Lund, Sweden.

c. Manchester X-Ray Imaging Facility, Research Complex at Harwell, Didcot, Oxfordshire, OX11 ODE, UK and School of Materials, University of Manchester, Manchester M13 9PL, UK.

d. Diamond Light Source, Oxfordshire, OX11 OFA, UK.

+ Electronic Supplementary Information (ESI) available: [details of any supplementary information available should be included here]. See
} DOI: $10.1039 / \mathrm{x} 0 \times x \times 0000 \mathrm{x}$ cycling in non-aqueous electrolyte, which lead to the growth of dendritic and/or mossy deposits across the electrode surface that can result in battery short circuits ${ }^{2-4}$, which are potential fire hazards. Various strategies, such as the use of solid polymer electrolytes, separators and ceramic coatings 5-8, liquid electrolyte additives ${ }^{9,10}$ and Li metal surface passivation ${ }^{11}$ have been developed to mitigate dendrite growth and moss formation. However, these approaches are currently not completely fail-safe; a detailed understanding of how these microstructures form and the conditions under which they can occur in a working battery cell is imperative for developing a definite solution to the problem of dendritic growth.

A range of diagnostic tools have been used by researchers to study the formation of dendritic/mossy microstructures in lithium batteries. Optical and electron microscopy have been used for two-dimensional (2D) characterization of electrodeposited $\mathrm{Li}$ microstructures and lithium metal surface morphology changes ${ }^{12-16}$, providing a wealth of qualitative information on their inherently three-dimensional (3D) structure. However, most of these studies were performed ex-situ, thus requiring cell disassembly and 
removal of the lithium microstructures from their as grown environment. NMR and MRI investigations are non-invasive and have been successfully carried out in-situ to capture the formation of dendritic and electrodeposited lithium structures 2,3; however the resolution of MRI is limited, typically $100 \mu \mathrm{m}^{17}$, and the presence of metals can introduce imaging artefacts ${ }^{18}$. There have also been reported attempts to theoretically model different electrodeposited Li growth with regards to their morphologies and feature size distributions $^{19-22}$.

X-ray computed tomography (CT) enables non-invasive acquisition of high spatial resolution $3 \mathrm{D}$ images of materials in-situ; however, applying tomographic imaging to Li can be rather challenging due to its low attenuation coefficient which limits X-ray absorption contrast. Recently, X-ray CT has been used to visualize metallic Li microstructures. Harry et al. ${ }^{4}$ first used synchrotron-based X-ray CT to image metallic Li microstructures in Li-polymer cells, demonstrating the role of subsurface dendritic structures within a Li metal electrode in the failure of lithium batteries. With bespoke $\mathrm{Li} / \mathrm{Li}$ symmetrical cells, Eastwood et al. ${ }^{23}$ used synchrotron X-ray phase contrast imaging to characterise different forms of $\mathrm{Li}$ microstructures. In this previous study, Eastwood et al. were able to distinguish between mossy metallic $\mathrm{Li}$ microstructures from high surface area lithium salt deposits by their contrasting X-ray attenuation. However, X-ray CT can be extended, using both synchrotron and lab-based X-ray sources, to explore temporal evolution of material microstructures within batteries during operation or failure 24-27, thus giving rise to the notion of "4-dimensional" tomography (i.e. 3D plus time) and even enabling quantitative information on 3D microstructural dynamics to be extracted. Recently, using synchrotron in-line phase contrast X-ray $\mathrm{CT}$, Sun et $a .^{28}$ non-destructively visualized the evolution of electrodeposited lithium, and observed separator cleavage caused by their growth. Here, we demonstrate the use of both synchrotron and laboratorybased X-ray micro-tomography to perform both in-situ and operando characterization and quantification of the morphological evolution that occurs at the surface of $\mathrm{Li}$ metal electrodes.

\section{Experimental}

\section{Electrode preparation and cell assembly}

Using custom-built thin-walled X-ray transparent PFA Swagelok cells ${ }^{27}$, half-cells were assembled in an argon-filled glove-box $\left(\mathrm{O}_{2}\right.$ and moisture level maintained at $\left.<0.5 \mathrm{ppm}\right)$ using metallic lithium as positive electrode, graphite as negative electrode, a borosilicate glass microfiber separator (Whatmann GF/B grade, thickness $650 \mu \mathrm{m}, \mathrm{GE}, \mathrm{UK}$ ), and $1 \mathrm{M}$ $\mathrm{LiPF}_{6}$ in $3: 7 \mathrm{vol} / \mathrm{vol}$ of ethylene carbonate (EC) : ethyl methyl carbonate (EMC) as electrolyte. Graphite electrodes were prepared as a slurry mixture containing graphite powder (TIMREX ${ }^{\circledR}$ SLP30, TIMCAL, Switzerland), carbon black (Super $P$, Sigma Aldrich, UK), and PVDF binder (Pi-KEM, UK) in the respective percentage weight ratios 87:3:10 in $n$-methylpyrrolidone (Pi-KEM, UK). This slurry was coated onto stainless steel current collecting pins, and dried at $80{ }^{\circ} \mathrm{C}$ under vacuum for $24 \mathrm{~h}$. The metallic lithium electrodes were cut out from a $200 \mu \mathrm{m}$ thick lithium foil (Pi-KEM, UK) into 3.2 $\mathrm{mm}$ diameter discs.

\section{Operando synchrotron X-ray tomography}

The morphological changes at the surface of a Li metal electrode during the first discharge of an assembled graphite/Li half-cell were examined using operando $\mathrm{X}$-ray CT. The synchrotron X-ray CT experiments were conducted at the Diamond-Manchester Imaging Branchline I13-2 of Diamond Light Source, UK. The experimental setup is shown in Figure 1. The mounted sample was electrically insulated from the sample stage to prevent interference. A partiallycoherent, polychromatic 'pink' beam ( 5 to $35 \mathrm{keV}$ ) of parallel geometry was used with an undulator gap of $5 \mathrm{~mm}$. The pink beam was chosen as it can provide higher signal-to-noise images with shorter exposure times, high temporal resolution and improved spatial resolution (due to decreased blurring), relative to a monochromatized beam. Compared to a monochromatic beam, the photon flux of the pink beam is about $50-100$ times higher ${ }^{29}$.

The beam was reflected from the Pt stripe of a grazingincidence focusing mirror and filtered with $950 \mu \mathrm{m}$ pyrolytic graphite, $2 \mathrm{~mm}$ aluminium and $20 \mu \mathrm{m}$ nickel. For each tomogram of the examined half-cell sample, 4000 projection images of exposure time $160 \mathrm{~ms}$ each were acquired at equally-spaced angles over $180^{\circ}$ of continuous rotation (along the sample's long axis) by a pco.edge 5.5 (PCO AG, Germany) detector. The detector was coupled to a $500 \mu \mathrm{m}$ $\mathrm{CdWO}_{4}$ scintillator and visual light optics, providing $8 \mathrm{x}$ total magnification, a field of view of $2.1 \times 1.8 \mathrm{~mm}(2560 \times 2160$ pixels) and an effective pixel size of $0.81 \mu \mathrm{m}$. A propagation distance of approximately $25 \mathrm{~mm}$ was used to provide minimal inline phase contrast. Prior to reconstruction via filtered back projection with DAWN $1.7^{30}$, projection images 
were flat and dark corrected, and ring artefact suppression was performed ${ }^{31}$.

Galvanostatic discharge of the half-cell from open circuit voltage (OCV) to $0.005 \mathrm{~V}$ was performed using a potentiostat (Ivium Compactstat, Ivium Technologies) at a rate of $20 \mathrm{mAg}$ ${ }^{1}$, which is estimated to be a C/20 C-rate based on graphite material mass. Tomograms of a central region within the half-cell were successively acquired every $15 \mathrm{~min}$ during discharge, including a rest period of $120 \mathrm{~s}$ between each successive tomogram acquisition.

(a)

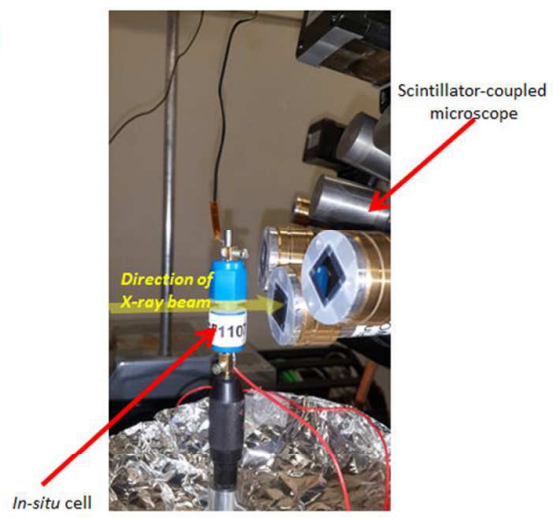

(b)

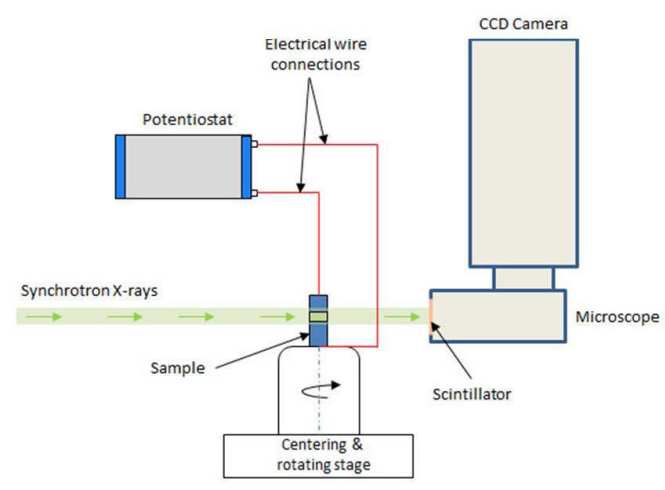

Figure 1. (a) Optical image of the in-situ cell mounted for synchrotron X-ray CT. (b) Schematic representation of the experimental beamline setup for operando synchrotron $\mathrm{X}$-ray CT.

\section{Time-lapse laboratory X-ray tomography}

To observe the effect of repeated charge-discharge cycling on the surface morphology of Li metal in-situ, X-ray CT was performed on another assembled graphite/Li half-cell using a microfocus tube 'laboratory source' X-ray microscopy system equipped with a tungsten anode target (ZEISS Xradia Versa 520, Carl Zeiss X-ray Microscopy Inc., USA). X-ray CT scans were performed on the half-cell in its original state, immediately after assembly, and after 10, 70 and 135 charge-discharge cycles. The half-cell was galvanostatically cycled at a C/5 C-rate between $0.005 \mathrm{~V}$ and $1.0 \mathrm{~V}$ using a battery cycler (Maccor 4300 series, USA).

For each tomographic image acquisition, the half-cell was mounted firmly onto a sample holder and placed on the rotating sample stage between the $\mathrm{X}$-ray source and a $2 k \times$ $2 k$ detector, as shown in Figure 2 . Tomography datasets were collected at $20 \times$ magnification in absorption-contrast mode. The projection image datasets were reconstructed using a commercial image reconstruction software package (ZEISS XMReconstructor, Carl Zeiss X-ray Microscopy Inc., Pleasanton, USA) which employs a filtered back-projection algorithm. Details of the experimental parameters for each tomographic scan are presented in Table 1. The tomograms were 3D median filtered using Avizo software (v9.1, FEI VSG, France) to reduce random image noise.

Table 1. Scan parameters for laboratory X-ray tomographic experiments.

\begin{tabular}{|c|c|c|c|c|}
\hline & $\begin{array}{c}0 \\
\text { cycles }\end{array}$ & $\begin{array}{c}10 \\
\text { cycles }\end{array}$ & $\begin{array}{c}70 \\
\text { cycles }\end{array}$ & $\begin{array}{c}135 \\
\text { cycles }\end{array}$ \\
\hline Source voltage (kV) & 50 & 35 & 50 & 50 \\
\hline $\begin{array}{l}\text { Radiograph exposure } \\
\text { time (s) }\end{array}$ & 75 & 66 & 66 & 66 \\
\hline Number of projections & 1601 & 3201 & 2151 & 2201 \\
\hline $\begin{array}{l}\text { Source-detector } \\
\text { distance }(\mathrm{mm})\end{array}$ & 29.4 & 29.5 & 29.3 & 29.6 \\
\hline Effective voxel size $(\mu \mathrm{m})$ & 0.75 & 0.75 & 0.75 & 0.75 \\
\hline
\end{tabular}

(a)

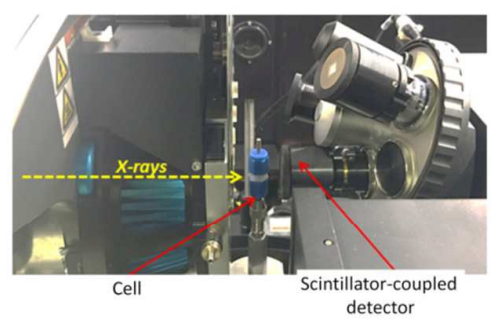

(b)

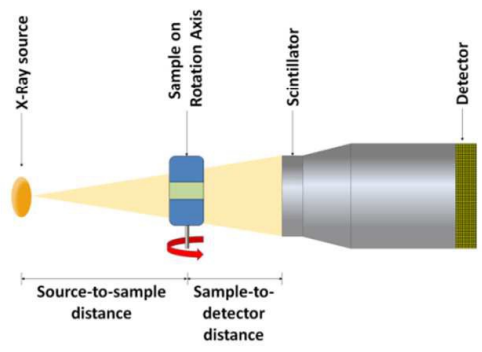

Figure 2. (a) Optical image of in-situ cell sample mounted for laboratory X-ray CT. (b) Schematic representation of experimental setup for laboratory X-ray CT. 
(a)

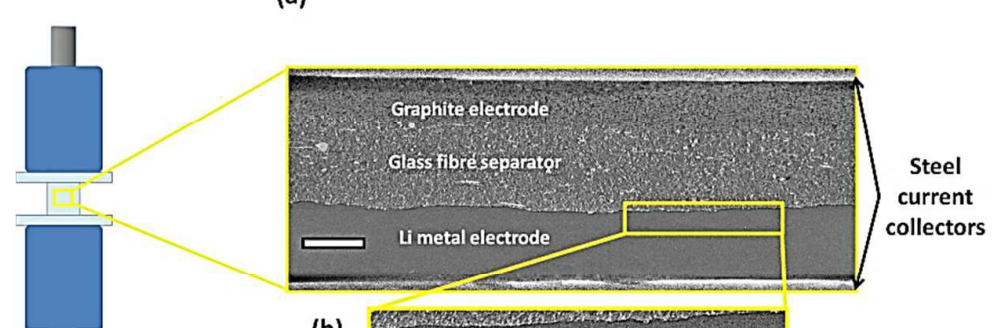

(b)

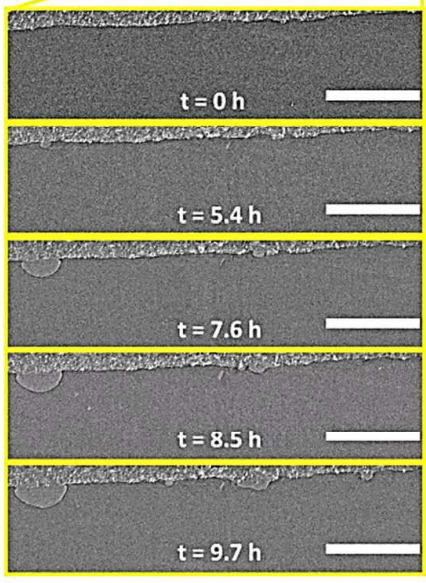

Figure 3. (a) X-ray tomogram cross-section through the half-cell assembly. (b) Magnified region of tomogram section showing gradual pit formation on the Li metal surface during cell discharge at a constant rate of $20 \mathrm{mAg}^{-1}$. Scale bars represent 200 $\mu \mathrm{m}$.

\section{Results and discussion}

\section{Operando X-ray CT synchrotron study during single discharge}

To track the 3D morphological evolution that occurs at the surface of Li metal electrodes in a rechargeable Li battery during the early stage of cell cycling, operando synchrotron X-ray CT was performed during the gradual discharge of graphite/Li half-cell assembled with a borosilicate glass-fibre separator. A total of 44 successive $\mathrm{X}$-ray tomograms were acquired in the course of the half-cell discharge.

Figure 3(a) shows a vertical cross section through the tomogram of a half-cell sample before operation, and Figure 3 (b) shows a selected sequence of time-resolved tomogram sections of a magnified region of interest that captures gradual pit formation along the Li metal electrode surface as a result of electrochemical discharge. Volume renderings of this magnified region [presented in Figure 4 and Figure 5(a)] provide qualitative insight into the $3 D$ morphological structure and evolution of these pits. The pits appear roughly hemispherical in shape and are seen to gradually increase in both diameter and depth as the half-cell discharge progresses. In Figure 5(b), a gradual increase in the volume fraction of pits within the analysed sample volume is clearly observed as a result of the cell discharge.

The occurrence of similar pit-like holes on the surface of cycled lithium electrodes has previously been identified using electron microscopy ${ }^{13,32-34}$. It was found that pit morphology and growth rate along the metallic Li electrode surfaces can be a function of electrolyte composition and applied current density. In addition, such electrochemically-induced pitting has been previously observed to be associated with the breakdown of the passive layer on the metal surface, which could be as a result of the penetration of $\mathrm{PF}_{6}{ }_{6}$ anions from the electrolyte through the passive layer, causing localized variations in interfacial energy and thus resulting in the local dissolution of the lithium metal surface ${ }^{35}$. Moreover, previous investigations also show that such lithium dissolution could take place preferentially along surface defects such as those induced during manufacturing or prior handling of the Li metal electrode ${ }^{13,36}$.

Although the primary investigation here was to visualize and track morphological changes occurring at the surface of the lithium metal electrode during the course of a single discharge, some other interesting observations were made. During exposure of the operating half-cell to the intense 


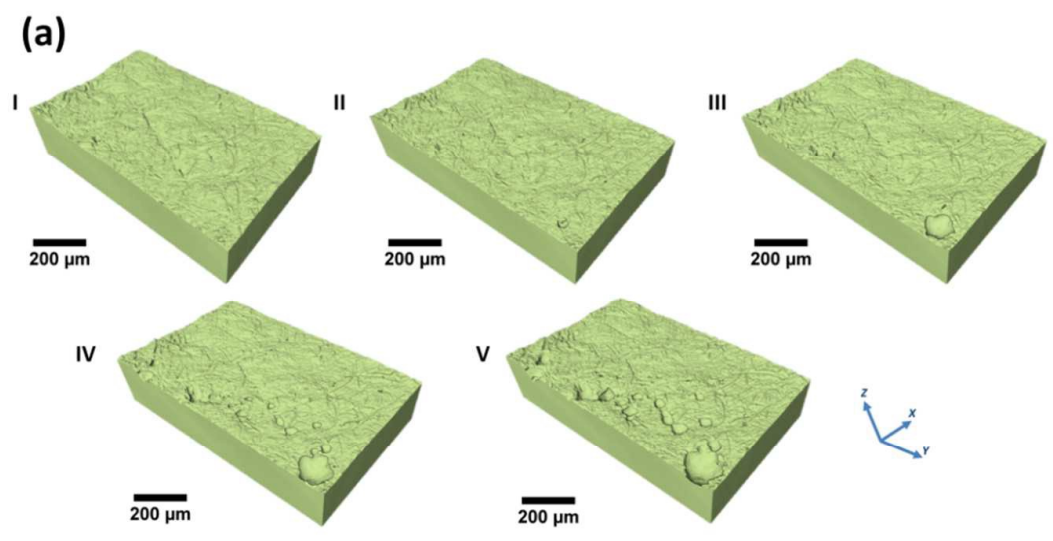

(b)

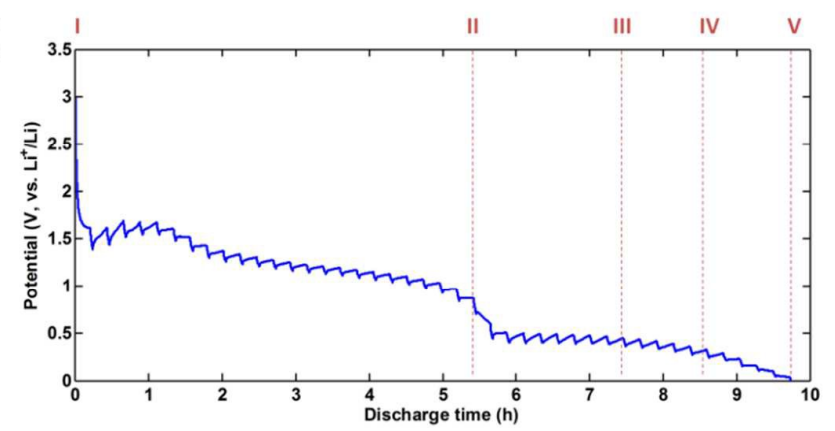

Figure 4. (a) 3D renderings of the lithium metal surface within the magnified region in Figure $3 \mathrm{~b}$ at different stages during the half-cell discharge at a constant rate of $20 \mathrm{mAg}-1$. The discharge voltage profile of the cell is plotted in (b) and relates the 3D renderings to time.

synchrotron radiation, a loss in cell performance as well as a deviation from the normal half-cell electrochemical behaviour was observed. Figure 6 shows the resulting electrochemical discharge profile of the graphite/Li half-cell during operando synchrotron $\mathrm{X}$-ray $\mathrm{CT}$. Sequential fluctuations or 'upward humps' in the voltage profile of the graphite/Li half-cell were seen, with their occurrence corresponding with tomogram acquisition periods when the sample was exposed to the pink beam. A typical graphite/Li half-cell discharge is normally associated with a decline in the cell voltage as shown by the red-dotted voltage profile in Figure 6. However, with the half-cells used in the X-ray experiments, increases in the half-cell voltage occurred each time the X-ray shutter was open, such as during each tomogram acquisition and flat-image acquisition where the half-cell sample was exposed to the high flux $X$-rays. Between each successive tomogram acquisition was a $120 \mathrm{~s}$ rest period during which the $X$-ray shutter was closed: during this period, the half-cell voltage reverts to the expected decreasing profile. These fluctuating trends in electrochemical behaviour are found to be similar to that previously observed during intermittent $X$-ray irradiation of $\mathrm{TiO}_{2}$ film electrodes, where exposure to synchrotron $X$-rays promoted photoelectrochemical reactions ${ }^{37}$, and also during exposure of low temperature fuel cells to high intensity synchrotron radiation ${ }^{38-40}$.

Significant degradation in half-cell discharge performance during exposure to the high intensity $\mathrm{X}$-ray beam was also observed - the discharge of the irradiated half-cell was completed in ca. 10 hours rather than an expected 20 hours based on the estimated $\mathrm{C} / 20$ current rate. Moreover, a lower specific discharge capacity of $159 \mathrm{mAhg}^{-1}$ was obtained with the irradiated cell while a discharge capacity of $370 \mathrm{mAhg}^{-1}$ achieved with no X-ray exposure.

To ensure that the observed performance degradation phenomenon was not caused from interference to the cell's electrical connections from sequential sample rotation / tomography acquisition, the beamline was set to radiography mode (i.e. no sample rotation) and the open circuit voltages of more identical graphite/Li half-cell samples were repeatedly measured during discharge with and 
without X-ray irradiation (i.e. when the X-ray shutter was in open or closed state). It was observed that even in radiography mode, oscillations in cell voltage similar to those observed in Figure 6 occurred in each of the irradiated cell samples whenever the X-ray shutter was opened or closed, in addition to shorter discharge times and lower discharge capacities. From these observations, it could be said that the exposure of the sample to the intense $\mathrm{X}$-ray beam induced performance degradation in the half-cell.

(a) 1

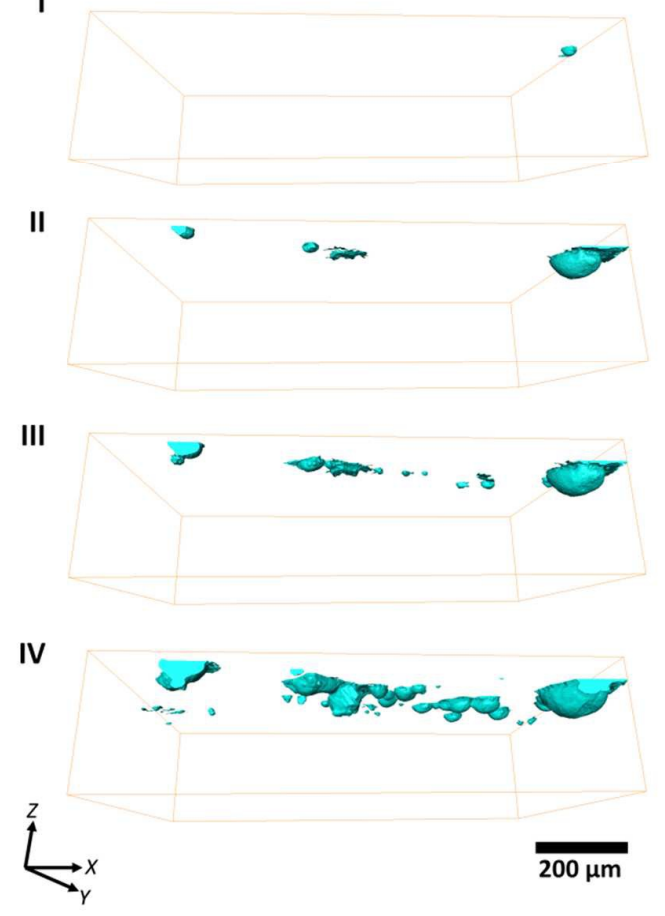

(b)

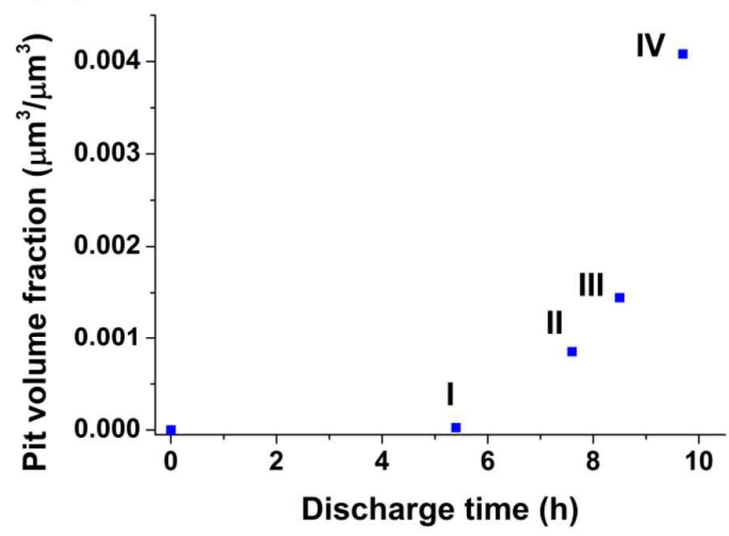

Figure 5. (a) Volume rendering of the pits formed along the lithium metal surface within the magnified region in Figure 4 at different stages of the half-cell discharge. (b) Variation of pit volume fraction with discharge time within the analysed sample region.

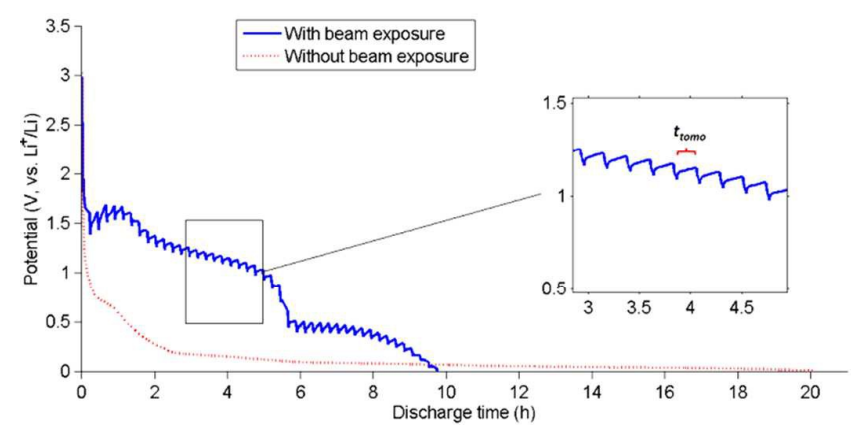

Figure 6. Discharge profile of the graphite/Li half-cell during operando CT (blue line) and without any exposure to the pink beam (red dotted line). Both half-cell discharges were performed at a $\mathrm{C} / 20$ current rate. Each tomogram acquisition period ( $\left.t_{\text {tomo }}\right)$ corresponded with the period of abnormal discharge voltage behaviour.

It is suspected that the observed performance degradation behaviour is the result of sample interaction with the ionising beam, causing increased internal resistances within the half-cell and thus a loss in performance. Similar degradation phenomena in electrochemical behaviour have been detected in lithium-ion full cells and half-cells containing $\mathrm{LiPF}_{6}$-based electrolytes that were exposed to ionising radiation: Ding et al. observed substantial deterioration in cell performance after gamma radiation exposure ${ }^{41-43}$ and attributed the decline in performance to the production of carboxyl groups in the electrolyte which react with active lithium metal, causing an increase in cell impedance and a decrease in charge and discharge capacity. Gamma radiation - induced capacity degradation has also been observed in lithium polymer cells ${ }^{44}$, with increased radiation dose in cells leading to shorter discharge time and lower specific capacity. Such electrochemical behaviour was not observed during operando X-ray $\mathrm{CT}$ experiments previously reported ${ }^{27,45}$ which employed a lower intensity monochromatic X-ray beam. Moreover, these findings highlight the need for careful consideration of radiation dose that would prevent performance losses in functional materials when using ionising beams such as X-rays are used as a diagnostic tool.

\section{Time-lapse laboratory X-ray CT study during repeated cycling}

To extend this investigation over longer battery operating times, the morphological transitions at the surface of a lithium metal electrode due to repeated charge-discharge cycling was examined over extended time periods in-situ 
using laboratory X-ray CT. Figure 7(a) shows tomogram crosssections through a graphite/Li half-cell at different stages in its cycle life. As seen in Figure 7(a), the half-cell components were distinctly resolved: the dark-grey topmost layer is the low-attenuating Li metal electrode; the middle layer is the glass-fibre separator with relatively highly attenuating microfibers and the porous graphite electrode at the bottom. Also captured in the tomogram is a clear outline of the $\mathrm{Li}$ metal surface in contact with the glass-fibre separator. The $\mathrm{Li}$ metal surface is originally smooth and almost featureless prior to cell assembly; however, pressure applied to the cell during assembly causes the separator microfibers to leave imprints upon contact with the soft Li metal surface, as seen

(a)
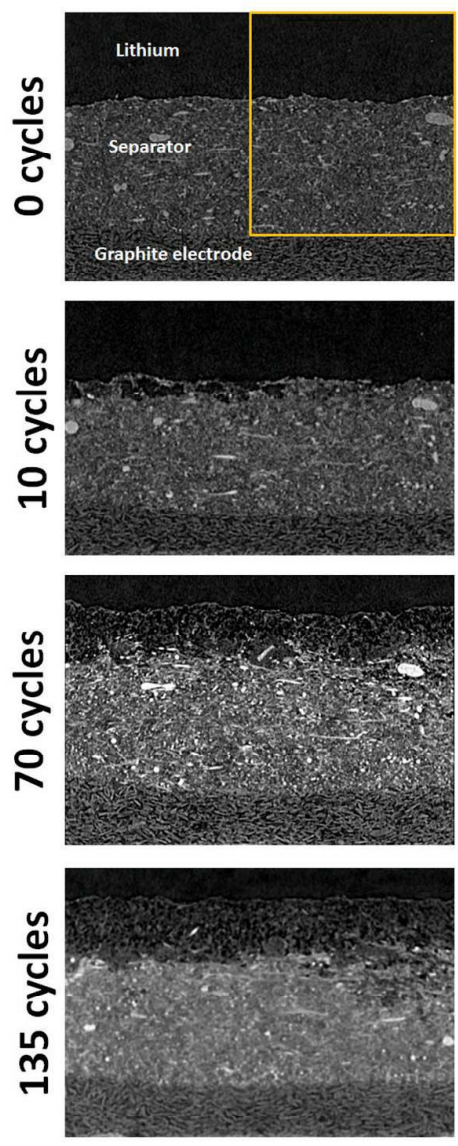

$100 \mu \mathrm{m}$ in the volume renderings of the Li surface in Figure 4(a).

After 10 cycles, the presence of a low attenuation, morphologically distinct layer is observed on the Li metal surface. The corresponding 3D rendering in Figure $7(\mathrm{~b})$ shows this layer to be a moss-like deposit, which appears to penetrate the surface of the fibrous separator. Such mosslike deposits, as well as dendrite formation, are known to occur as a result of non-uniform lithium electro-deposition during repeated charge and discharge cycles. Previous investigations using electron microscopy (e.g. ${ }^{12,13,36,46}$ ) have shown that lithium moss and dendrite nucleation and growth upon subsequent Li deposition during charge cycling takes place preferentially along dissolution pits such as those

(b)

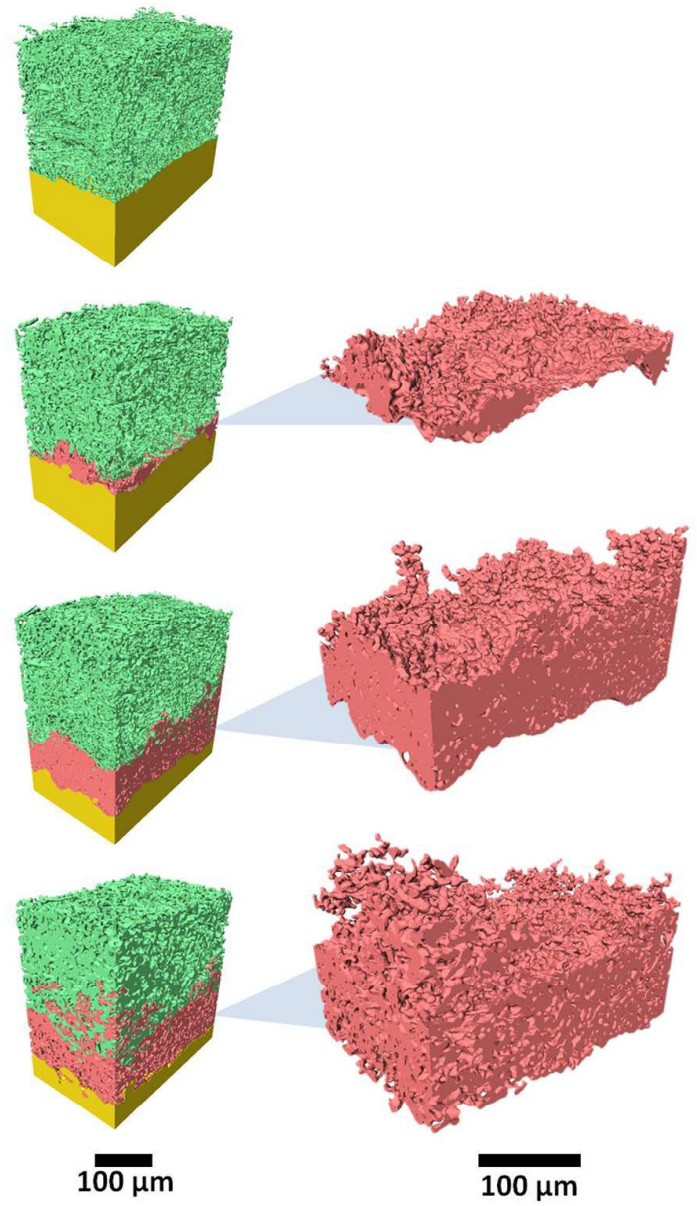

Figure 7. (a) Vertical cross-sections through the tomogram of the half-cell at different cycle number. The orange rectangle in the panel at 0 cycles indicates the sub-volume of interest extracted in each acquired tomogram for subsequent analysis. The white scale bars represents $100 \mu \mathrm{m}$. (b) Corresponding 3D renderings of the sub-volume of interest highlighted at different cycle numbers, where the separator is shown as green, the mossy lithium phase is shown as pink, and the non-porous residual lithium layer is shown as yellow. 
(a)

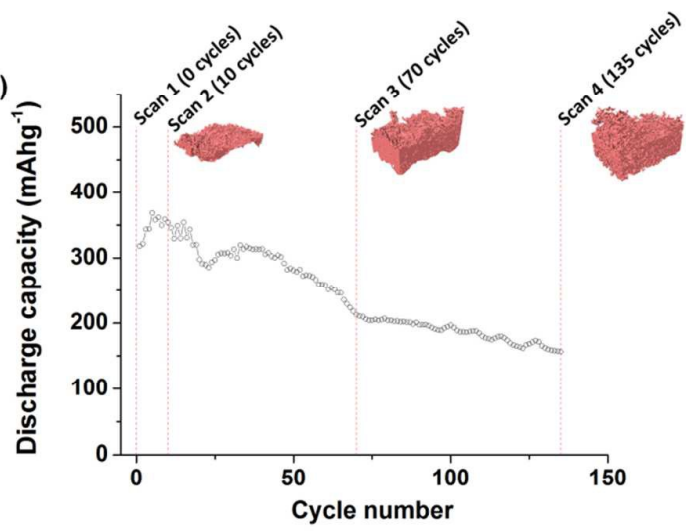

(c)

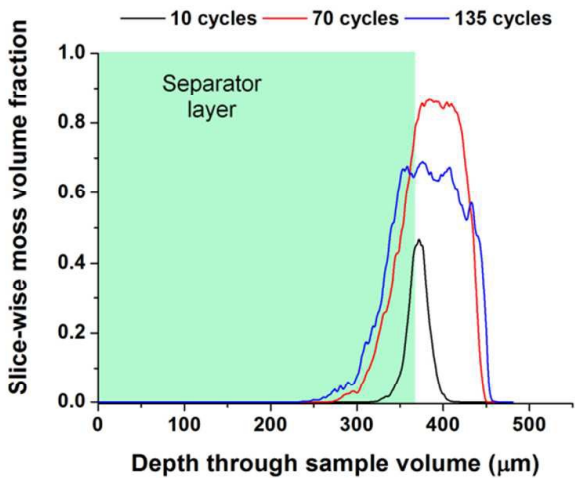

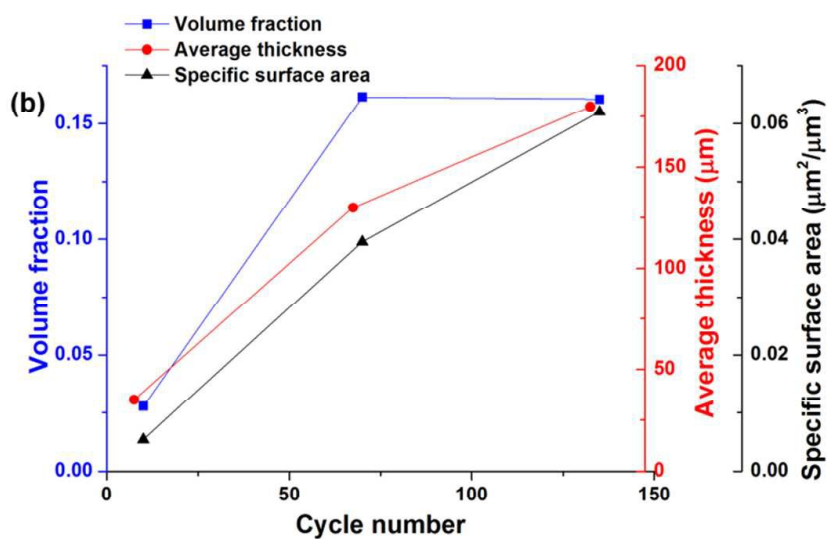

(d)

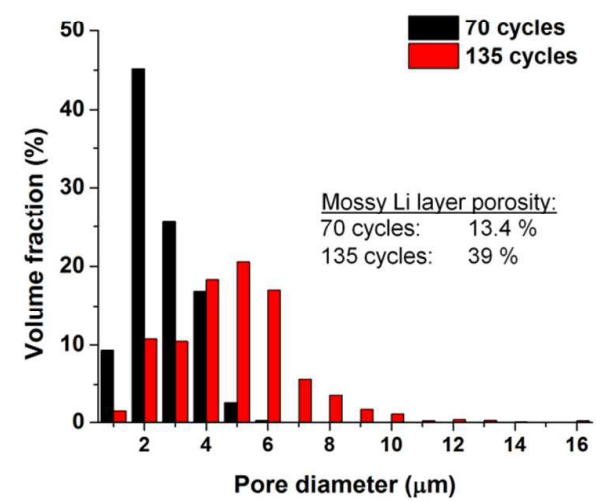

Figure 8. Cycle performance of the in situ graphite/Li half-cell. Red dashed lines mark each tomogram acquisition point, and volume renderings of the mossy lithium formed are shown at each marked cycle stage. (b) Variation in 3D moss volume fraction, average thickness and specific surface area of the entire porous mossy lithium layer with cycle number. (c) Slice-wise variation of Li moss volume fraction along the $Z$-axis direction (sample volume depth) at different cycle number. (d) Pore size distribution within the porous mossy lithium layer at 70 and 135 cycles. Pore size distribution was calculated using the continuous pore size distribution method ${ }^{49}$.

identified in the operando CT study. This has been attributed to locally enhanced current densities at such regions on the electrode surface. As the cell cycling progresses, the lithium moss is seen to gradually increase in thickness and penetrate through the fibrous separator [Figure $7(b)$ ]. These deposits can continually grow through the separator to create contact between both electrodes and initiate internal short-circuits, which could lead to hazardous battery failure via short circuiting. Dendritic growth within lithium batteries continues to present significant safety risks; as such, there are currently research efforts into their early detection within the batteries before short circuiting occurs ${ }^{47}$. Furthermore, these imaging results highlight the influence of separator selection on the overall performance and safety of lithium batteries: highly tortuous, less porous separators are favourable in suppressing dendrite growth and contact between electrodes that can cause short circuits; however, such separator structure does not promote high rate capability and fast ion transport.
The cycling performance of the graphite-Li half-cell is presented in Figure 8(a). After 135 cycles, the graphite/Li half-cell showed a $51 \%$ drop in capacity. The apparent capacity fade seems typical of cells containing Li electrodes, as repeated cycling of Li electrodes leads to continuous SEI layer formation, causing significant Coulombic efficiency losses, lithium consumption, and increased cell impedance ${ }^{48}$.

The mossy lithium deposited on the metallic Li electrode surface forms a porous, micro-structured layer that gradually penetrates through the microfiber separator. As shown in Figure $8(\mathrm{~b})$, the volume and thickness of the mossy Li layer increase as cell cycling progresses. The mean thickness of the mossy layer measured from the surface of the metallic $\mathrm{Li}$ electrode after 10 cycles was $35 \mu \mathrm{m}$. After 70 cycles, the mossy layer thickness increased to $130 \mu \mathrm{m}$ (with $65 \mu \mathrm{m}$ of the mossy layer penetrating the microfiber separator) and to $180 \mu \mathrm{m}$ (with $100 \mu \mathrm{m}$ of the layer penetrating the microfiber separator) after 135 cycles. Moreover, the thickness and volume of the residual (unreacted) lithium electrode is seen 
to decrease as the cell cycling progresses. These observations are in good agreement with Lopez et al. ${ }^{12}$ who, using scanning electron microscopy, identified the presence of a thin dendritic layer (a few micrometres thick) on top of a dense porous mossy layer (several tens of micrometres thick) growing above the residual Li metal, and observed that the thickness of the micro-structured layers increase significantly with repeated cycling.

Phase volume fraction and pore size distribution information were also extracted from the mossy layer in the image reconstructions. Here, the moss volume fraction is taken as the fraction of the mossy lithium volume within the analysed sample volume, and pore size calculations were performed only on the porous mossy lithium layer using the continuous pore size distribution method ${ }^{49}$. In Figure 8(b), the 3D moss volume fraction within the analysed sample volume increases from 0.026 after 10 cycles to 0.16 after 70 cycles and appears to remain fairly constant at 135 cycles. However, after a 2D slice-wise examination of the moss volume fraction using a stereological relationship ${ }^{50}$, a decrease in slice-wise volume fraction of the Li moss is observed along the $z$-height (through-plane direction) of the sample volume between 70 and 135 cycles, as shown in Figure 8 (c). This decrease can be attributed to the increase in porosity of the mossy layer with repeated cycling. In the tomogram taken after 70 cycles, the porous nature of the mossy layer was revealed with a measured porosity of 13.4 $\%$ which increased to $39 \%$ after 135 cycles. Porosity information on the mossy layer was not extracted after 10 cycles, as the porous nature of the mossy microstructure could not be sufficiently resolved at the employed imaging length scale. Moreover, the pore size distribution information extracted from within the mossy layer, which is presented in Figure $8(d)$, shows that there is a clear increase in the pore size within the mossy lithium layer, with the average pore size increasing from $3.1 \mu \mathrm{m}$ to $5.3 \mu \mathrm{m}$ between 70 and 135 cycles. The observed increase in porosity and pore size could be attributed to occurrence of heterogeneous dissolution within the mossy microstructure during repeated charge cycling, which could also lead to the formation of electrically isolated $\mathrm{Li}^{51}$. The pore sizes are in good agreement with previous research ${ }^{12}$. Also, the specific surface area of the mossy lithium microstructure is seen to increase with cycling in Figure 8(b), which can be related to the increase in porosity and pore size within the mossy layer.

This journal is (C) The Royal Society of Chemistry 20xx

\section{Conclusions}

The morphological changes that occur at the surface of $\mathrm{Li}$ metal electrodes in rechargeable $\mathrm{Li}$ batteries have been characterised in-situ and operando with X-ray tomographic imaging using both synchrotron and laboratory based X-ray sources. Operando synchrotron X-ray CT enabled the real time 3D visualization of pit formation at the Li metal surface due to Li dissolution. Time-lapse laboratory X-ray CT imaging was used to track the growth of moss-like lithium deposits at the Li electrode surface over longer periods of cycling. The 3D imaging data showed the appearance of pit-like holes on the Li metal surface as a result of Li dissolution during the first discharge, and the formation of a mossy, microstructured lithium layer that increased in thickness with repeated cell cycling, penetrating the separator in the process. The results also highlight the importance of separator morphology in controlling or preventing dendrite growth in high tortuosity separators within commercial lithium batteries.

Microstructural parameters such as phase volume fraction, pore size distribution, and specific surface area were used to quantitatively track the evolving microstructure of the metal electrode surface. The porosity and specific surface area of the mossy lithium layer formed upon repeated cycling are seen to increase with cycle number, most likely due lithium dissolution, and further dissolution could lead to the formation of electrically isolated lithium and thus reduced cell capacity. Analysis of the mass balance of Li between the mossy micro-structured layer and the residual unreacted $\mathrm{Li}$ layer was not conducted here because the Li metal electrode used in this study (3.2 mm diameter) was larger than the $X$ ray field of view (ca. $1 \mathrm{~mm}$ wide). However, the aid of an electrode assembly design smaller than the employed X-ray field of view, future experiments will look at quantitatively tracking the amount of $\mathrm{Li}$ consumed during Li dissolution and the amount of mossy $\mathrm{Li}$ deposited via material balance calculations. It is also of interest to the authors to exploit even higher resolution X-ray microscopy to resolve both physically and chemically distinct nanoscale regions at the evolving surface of the bulk electrode, just as was previously applied to catalytic solids ${ }^{52}$.

Although the high flux of the synchrotron pink beam provided sufficient resolution and contrast that enabled identification and tracking of surface morphology changes within the low attenuating Li metal, beam exposure to the sample led to performance degradation. Based on the 
findings from the synchrotron CT experiments, the X-ray radiation dose to the cell samples must be carefully considered to prevent material degradation and cell performance losses.

\section{Acknowledgements}

The authors would like to thank Diamond Light Source for the award of beamtime under proposal MT11539 and the staff of the Diamond-Manchester Imaging Branchline 113-2. We also thank Dr. Kaz Wanelik for technical support with synchrotron tomographic image reconstructions and data retrieval. The work was supported by the UK EPSRC (under grants EP/N001583/1, EP/N032888/1, EP/M009394/1), UCL BEAMS and the Royal Academy of Engineering. Access to the Zeiss Xradia Versa 520 was supported by the UK EPSRC and UCL.

\section{References}

1 W. Xu, J. Wang, F. Ding, X. Chen, E. Nasybulin, Y. Zhang and J.-G. Zhang, Lithium metal anodes for rechargeable batteries, Energy Environ. Sci., 2014, 7, 513-537.

2 R. Bhattacharyya, B. Key, H. Chen, A. S. Best, A. F. Hollenkamp and C. P. Grey, In situ NMR observation of the formation of metallic lithium microstructures in lithium batteries., Nat. Mater., 2010, 9, 504-510.

3 S. Chandrashekar, N. M. Trease, H. J. Chang, L.-S. Du, C. P. Grey and A. Jerschow, 7Li MRI of Li batteries reveals location of microstructural lithium., Nat. Mater., 2012, 11, 311-315.

4 K. J. Harry, D. T. Hallinan, D. Y. Parkinson, A. A. MacDowell and N. P. Balsara, Detection of subsurface structures underneath dendrites formed on cycled lithium metal electrodes., Nat. Mater., 2014, 13, 69-73.

5 B. Scrosati, Recent advances in lithium ion battery materials, Electrochim. Acta, 2000, 45, 2461-2466. X. Yu, A Stable Thin-Film Lithium Electrolyte: Lithium Phosphorus Oxynitride, J. Electrochem. Soc., 1997, 144, 524-532.

7 G. M. Stone, S. A. Mullin, A. A. Teran, D. T. Hallinan, A. M. Minor, A. Hexemer and N. P. Balsara, Resolution of the Modulus versus Adhesion Dilemma in Solid Polymer Electrolytes for Rechargeable Lithium Metal Batteries, J. Electrochem. Soc., 2012, 159, A222-A227.
S. Augustin, V. Hennige, G. Hörpel and C. Hying, Ceramic but flexible: new ceramic membrane foils for fuel cells and batteries, Desalination, 2002, 146, 23-28.

O. Crowther and A. C. West, Effect of Electrolyte Composition on Lithium Dendrite Growth, J. Electrochem. Soc., 2008, 155, A806-A811.

T. Hirai, Effect of Additives on Lithium Cycling Efficiency, J. Electrochem. Soc., 1994, 141, 23002305.

F. Marchioni, K. Star, E. Menke, T. Buffeteau, L. Servant, B. Dunn and F. Wudl, Protection of lithium metal surfaces using chlorosilanes., Langmuir, 2007, 23, 11597-11602.

C. M. López, J. T. Vaughey and D. W. Dees, Morphological Transitions on Lithium Metal Anodes, J. Electrochem. Soc., 2009, 156, A726-A729.

L. Gireaud, S. Grugeon, S. Laruelle, B. Yrieix and J.-M. Tarascon, Lithium metal stripping/plating mechanisms studies: A metallurgical approach, Electrochem. commun., 2006, 8, 1639-1649.

Y. Qi and S. J. Harris, In Situ Observation of Strains during Lithiation of a Graphite Electrode, J. Electrochem. Soc., 2010, 157, A741-A747.

J. Steiger, D. Kramer and R. Mönig, Mechanisms of dendritic growth investigated by in situ light microscopy during electrodeposition and dissolution of lithium, J. Power Sources, 2014, 261, 112-119.

P. Bai, J. Li, F. R. Brushett and M. Z. Bazant, Transition of lithium growth mechanisms in liquid electrolytes, Energy Environ. Sci., , DOI:10.1039/C6EE01674J.

J. A. Tang, S. Dugar, G. Zhong, N. S. Dalal, J. P. Zheng, Y. Yang and R. Fu, Non-destructive monitoring of charge-discharge cycles on lithium ion batteries using ${ }^{7}$ Li stray-field imaging., Sci. Rep., 2013, 3, 2596 (1-6).

M. M. Britton, P. M. Bayley, P. C. Howlett, A. J. Davenport and M. Forsyth, In Situ, Real-Time Visualization of Electrochemistry Using Magnetic Resonance Imaging., J. Phys. Chem. Lett., 2013, 4, 3019-3023.

J. Yamaki, S. Tobishima, K. Hayashi, Y. Nemoto and M. Arakawa, A consideration of the morphology of electrochemically deposited lithium in an organic electrolyte, J. Power Sources, 1998, 74, 219-227.

C. Monroe and J. Newman, Dendrite Growth in Lithium/Polymer Systems, J. Electrochem. Soc., 2003, 
150, A1377-A1384.

21 J.-N. Chazalviel, Electrochemical aspects of the generation of ramified metallic electrodeposits, Phys. Rev. A, 1990, 42, 7355-7367.

D. R. Ely and R. E. Garcia, Heterogeneous Nucleation and Growth of Lithium Electrodeposits on Negative Electrodes, J. Electrochem. Soc., 2013, 160, A662A668.

23 D. S. Eastwood, P. M. Bayley, H. J. Chang, O. O. Taiwo, J. Vila-Comamala, D. J. L. Brett, C. Rau, P. J. Withers, P. R. Shearing, C. P. Grey and P. D. Lee, Three-dimensional characterization of electrodeposited lithium microstructures using synchrotron X-ray phase contrast imaging., Chem. Commun. (Camb)., 2014, 51, 266-268.

D. P. Finegan, E. Tudisco, M. Scheel, J. B. Robinson, O. O. Taiwo, D. S. Eastwood, P. D. Lee, M. Di Michiel, B. Bay, S. A. Hall, G. Hinds, D. J. L. Brett and P. R. Shearing, Quantifying Bulk Electrode Strain and Material Displacement within Lithium Batteries via High-Speed Operando Tomography and Digital Volume Correlation, Adv. Sci., 2015, 3, 1500332(111).

D. P. Finegan, M. Scheel, J. B. Robinson, B. Tjaden, I. Hunt, T. J. Mason, J. Millichamp, M. Di Michiel, G. J. Offer, G. Hinds, D. J. L. Brett and P. R. Shearing, Inoperando high-speed tomography of lithium-ion batteries during thermal runaway., Nat. Commun., 2015, 6, 6924 (1-10).

J. M. Paz-Garcia, O. O. Taiwo, E. Tudisco, D. P. Finegan, P. R. Shearing, D. J. L. Brett and S. A. Hall, 4D Analysis of the Microstructural Evolution of Si-based Electrodes during Lithiation : Time-lapse X-ray Imaging and Digital Volume Correlation, J. Power Sources, 2016, 320, 196-203.

27 M. Ebner, F. Marone, M. Stampanoni and V. Wood, Visualization and quantification of electrochemical and mechanical degradation in Li ion batteries., Science, 2013, 342, 716-720.

F. Sun, L. Zielke, H. Markötter, A. Hilger, D. Zhou, R. Moroni, R. Zengerle, S. Thiele, J. Banhart and I. Manke, Morphological Evolution of Electrochemically Plated/Stripped Lithium Microstructures Investigated by Synchrotron X-ray Phase Contrast Tomography, ACS Nano, 2016, 10, 7990-7997.

C. Rau and C.-P. Richter, Imaging cochlear soft tissue displacement with coherent x-rays, Phys. Scr., 2015, 90, 108006 (1-6).
M. Basham, J. Filik, M. T. Wharmby, P. C. Y. Chang, B. El Kassaby, M. Gerring, J. Aishima, K. Levik, B. C. A. Pulford, I. Sikharulidze, D. Sneddon, M. Webber, S. S. Dhesi, F. Maccherozzi, O. Svensson, S. Brockhauser, G. Náray and A. W. Ashton, Data Analysis WorkbeNch (DAWN), J. Synchrotron Radiat., 2015, 22, 853-858.

S. Titarenko, P. J. Withers and A. Yagola, An analytical formula for ring artefact suppression in X-ray tomography, Appl. Math. Lett., 2010, 23, 1489-1495.

M. Arakawa, S. Tobishima, Y. Nemoto, M. Ichimura and J. Yamaki, Lithium electrode cycleability and morphology dependence on current density, J. Power Sources, 1993, 43, 27-35.

I. Yoshimatsu, Lithium Electrode Morphology during Cycling in Lithium Cells, J. Electrochem. Soc., 1988, 135, 2422-2427.

D. Aurbach, Y. Gofer and J. Langzam, The Correlation Between Surface Chemistry, Surface Morphology, and Cycling Efficiency of Lithium Electrodes in a Few Polar Aprotic Systems, J. Electrochem. Soc., 1989, 136, 3198-3205.

E. E. Abd El Aal, Effect of $\mathrm{Cl}^{-}$anions on zinc passivity in borate solution, Corros. Sci., 2000, 42, 1-16.

A. Yalamanchili, Uppsala Universitet, Masters thesis, 2014.

K. Tamura, Y. Ohko, H. Kawamura, H. Yoshikawa, T. Tatsuma, A. Fujishima and J. Mizuki, X-ray induced photoelectrochemistry on $\mathrm{TiO}_{2}$, Electrochim. Acta, 2007, 52, 6938-6942.

A. Schneider, C. Wieser, J. Roth and L. Helfen, Impact of synchrotron radiation on fuel cell operation in imaging experiments, J. Power Sources, 2010, 195, 6349-6355.

J. Roth, J. Eller and F. N. Buchi, Effects of Synchrotron Radiation on Fuel Cell Materials, J. Electrochem. Soc., 2012, 159, F449-F455.

J. Eller, T. Rosén, F. Marone, M. Stampanoni, A. Wokaun and F. N. Büchi, Progress in In Situ X-Ray Tomographic Microscopy of Liquid Water in Gas Diffusion Layers of PEFC, J. Electrochem. Soc., 2011, 158, B963-B970.

N. Ding, J. Zhu, Y. X. Yao and C. H. Chen, The effects of $\mathrm{Y}$-radiation on $\mathrm{LiCoO}_{2}$, Chem. Phys. Lett., 2006, 426, 324-328. 
of gamma-radiation on lithium-ion cells, Electrochim. Acta, 2006, 51, 6320-6324.

43 N. Ding, X. Fang, J. Xu, Y. X. Yao, J. Zhu and C. H. Chen, Performance of lithium-ion cells with a $y$-ray radiated electrolyte, J. Appl. Electrochem., 2008, 39, 995-1001.

44 D. He, Ohio State University, Masters thesis, 2014.

45 C. Villevieille, M. Ebner, J. L. Gómez-Cámer, F. Marone, P. Novák and V. Wood, Influence of conversion material morphology on electrochemistry studied with operando X-ray tomography and diffraction., Adv. Mater., 2015, 27, 1676-1681.

46 J. Wandt, C. Marino, H. A. Gasteiger, P. Jakes, R.-A. Eichel and J. Granwehr, Operando electron paramagnetic resonance spectroscopy - formation of mossy lithium on lithium anodes during chargedischarge cycling, Energy Environ. Sci., 2015, 8, 13581367.

47 H. Wu, D. Zhuo, D. Kong and Y. Cui, Improving battery safety by early detection of internal shorting with a bifunctional separator., Nat. Commun., 2014, 5, 1-6.

48 R. Younesi, G. M. Veith, P. Johansson, K. Edström and T. Vegge, Lithium salts for advanced lithium batteries: $\mathrm{Li}-$ metal, $\mathrm{Li}-\mathrm{O}_{2}$, and $\mathrm{Li}-\mathrm{S}$, Energy Environ. Sci., 2015, 8, 1905-1922.

49 B. Münch and L. Holzer, Contradicting Geometrical Concepts in Pore Size Analysis Attained with Electron Microscopy and Mercury Intrusion, J. Am. Ceram. Soc., 2008, 91, 4059-4067.

50 O. O. Taiwo, D. P. Finegan, D. S. Eastwood, J. L. Fife, L. D. Brown, J. A. Darr, P. D. Lee, D. J. L. Brett and P. R. Shearing, Comparison of three-dimensional analysis and stereological techniques for quantifying lithium-ion battery electrode microstructures., J. Microsc., 2016, 1-13.

51 M. Arakawa, S. Tobishima, Y. Nemoto, M. Ichimura and J. Yamaki, Lithium electrode cycleability and morphology dependence on current density, J. Power Sources, 1993, 43, 27-35.

52 I. D. Gonzalez-Jimenez, K. Cats, T. Davidian, M. Ruitenbeek, F. Meirer, Y. Liu, J. Nelson, J. C. Andrews, P. Pianetta, F. M. F. de Groot and B. M. Weckhuysen, Hard X-ray Nanotomography of Catalytic Solids at Work, Angew. Chemie Int. Ed., 2012, 51, 1198611990. 